\title{
Participation in Co-Curricular Activities and the Development of Engineering Identity
}

\section{Dr. Debra A Major, Old Dominion University}

Debra A. Major, Professor and Eminent Scholar at Old Dominion University (ODU), earned her Ph.D. in Industrial/Organizational Psychology from Michigan State University. Her research focuses on broadening participation in STEM. She is particularly interested in barriers encountered by women and ethnic minorities in college and in the workforce. Her work has received continuous funding from the National Science Foundation for over 15 years, and she has led numerous multidisciplinary and multi-institutional research teams. Dr. Major is fellow of the American Psychological Association, the Association for Psychological Science, the Society for Industrial and Organizational Psychology and the Society for the Psychology of Women.

\section{Seterra D. Burleson, Old Dominion University}

Seterra is a doctoral student in the industrial-organizational psychology program at Old Dominion University. Prior to entering her graduate studies, she received her BS in Psychology at the University of Montana and served in Peace Corps Perú for 27 months and worked in human services in Portland, OR. She received her MS at ODU and is now pursuing her PhD. She currently works as a research assistant in the Career Development Lab with Dr. Debra A. Major where she has contributed to several grant-funded projects concerning the underrepresentation of women and minorities in STEM from their undergraduate careers into the workforce. Her primary research interests include the work-life interface, workplace gender and cultural issues, and leader support.

\section{Xiaoxiao Hu, West Virginia University}

Xiaoxiao Hu is an Associate Professor in the Management Department at West Virginia University. She received her $\mathrm{PhD}$ in Industrial/Organizational psychology from George Mason University. Her primary research areas are on affective experience and relational dynamics in the workplace. She also does research on psychometric and measurement issues as well as cross-cultural comparisons between the East and the West. Her work has appeared in journals including Journal of Organizational Behavior, Journal of Vocational Behavior, and Journal of Managerial Psychology. She currently serves on the editorial board of Journal of Business and Psychology.

\section{Dr. Kristi J. Shryock, Texas A\&M University}

Dr. Kristi J. Shryock is the Frank and Jean Raymond Foundation Inc. Endowed Instructional Associate Professor and Associate Department Head in the Department of Aerospace Engineering in the College of Engineering at Texas A\&M University. She also serves as Director of the Craig and Galen Brown Engineering Honors Program. She received her BS, MS, and PhD from the College of Engineering at Texas A\&M. Kristi works to improve the undergraduate engineering experience through evaluating preparation in areas, such as mathematics and physics, evaluating engineering identity and its impact on retention, incorporating non-traditional teaching methods into the classroom, and engaging her students with interactive methods. 


\section{Participation in Co-Curricular Activities and the Development of Engineering Identity}

\section{Background and Objective}

The retention of undergraduate students in engineering majors is essential to improving graduation rates and to ultimately ensuring the health and vitality of the engineering workforce [1]. Engineering identity, the degree to which engineering is central to a student's self-concept, is a professional role identity that students typically develop during college [2]. Research has shown that engineering identity is predictive of both educational and professional persistence [3], [4]. Thus, investigating the factors that facilitate the development of engineering identity contributes to a more comprehensive understanding of retention in engineering.

Professional identity develops as individuals participate in the activities associated with the professional role, develop social networks linked to the profession, and engage in a sensemaking process in which they compare expectations and opportunities associated with the professional role to their personal interests and abilities [5]. For undergraduate engineering majors, participation in co-curricular activities may be an avenue through which engineering identity develops. In this study, we examined the relationship between participation in cocurricular activities and the development of engineering identity during the freshman year.

\section{Research Design}

\section{Participants and Procedure}

Freshman students at a large southwestern engineering school were surveyed at three time points: prior to the start of fall semester before having taken any engineering courses (Time 1), at the close of fall semester of their first year (Time 2), and at the close of spring semester of their first year (Time 3). Students were provided time during summer orientation to complete the Time 1 survey and class time to complete the Time 2 and Time 3 surveys. Results are based on responses from 1,211 freshman engineering students across two Cohorts (i.e., years of entry into engineering).

Cohort A consisted of 448 respondents (37.0\%). Cohort B included participants who entered as freshmen the following school year and consisted of 763 respondents (63.0\%). Participants were largely male $(70.9 \%)$ and either White $(57.7 \%)$ or Hispanic or Latino $(22.4 \%)$ with a mean age of entry into undergraduate studies of $18.29(S D=1.42)$ years.

\section{Measures}

Participation in professional development activities for fall and spring semester of participants' freshman year in college was assessed through self-report at the end of the freshman year (Time $3)$. Students reported whether they had completed any of the following in fall semester, spring semester, or both: (1) engaged in research, (2) served as an engineering student ambassador, (3) served as a peer mentor, (4) engaged in an internship, (5) participated in a student organization directly related to engineering, and (6) participated in a student organization outside engineering. 
The five-item measure of engineering identity utilized in the present study was developed and validated as part of a larger National Science Foundation (NSF) Improving Undergraduate STEM Education (IUSE) project [6]. Engineering identity was measured at Time 1, reflecting engineering identity prior to the start of students' first semester in college (i.e., pre-entry engineering identity); Time 2, reflecting engineering identity at the end of the first semester; and Time 3, reflecting engineering identity at the end of the spring semester.

Demographic control variables, including gender, age, and ethnicity, were gathered through university records.

\section{Results}

In the fall semester, $24(2.0 \%)$ students engaged in research, $7(0.6 \%)$ served as engineering student ambassadors, $6(0.5 \%)$ were peer mentors, $10(0.8 \%)$ engaged in internships, 300 $(25.0 \%)$ participated in student organizations directly related to engineering, and $212(17.7 \%)$ participated in student organizations outside engineering. In the spring semester, $68(5.7 \%)$ students were involved in research, $20(1.7 \%)$ served as engineering student ambassadors, 10 $(0.8 \%)$ were peer mentors, $32(2.7 \%)$ engaged in internships, $394(32.8 \%)$ participated in engineering student organizations, and $241(20.1 \%)$ participated in student organizations outside engineering.

Hierarchical multiple regression analyses showed that, when controlling for students' gender, age, ethnicity, and pre-entry engineering identity, engaging in internships in the fall was negatively associated with students' engineering identity at the end of their freshman year ( $\beta$ $=-1.00, p=.006$ ) and participation in student organizations directly related to engineering in the spring was positively associated with engineering identity $(\beta=.09, p=.044)$. No other activities were found to significantly relate to engineering identity at the end of fall or spring semesters.

\section{Conclusion}

The findings demonstrate that the timing and type of co-curricular activity in which students engage differentially influence the development of engineering identity. The negative relationship between taking an internship in the fall and engineering identity suggests that participation in such an intensive co-curricular activity early in one's academic career can be detrimental to the development of engineering identity. In contrast, the positive relationship between participation in engineering organizations in the spring of freshman year and engineering identity suggests that one semester's worth of experience in the major may be sufficient for certain types of extracurricular activities to benefit engineering identity. Given the low rates of participation in co-curricular activities during the freshman year, efforts should be concentrated on increasing participation in activities that may benefit students most, such as participating in engineering student organizations. The findings presented are part of a larger project supported by the NSF under Grant No. 1504741. 


\section{References}

[1] National Academy of Engineering, "Understanding the Educational and Career Pathways of Engineers," The National Academies Press, Washington, DC, USA, 2018, doi: $10.17226 / 25284$.

[2] S. L. Rodriguez, C. Lu, \& M. Bartlett, "Engineering identity development: A review of the higher education literature," International Journal of Education in Mathematics, Science and Technology (IJEMST), vol. 6, no. 3, pp. 254-265, 2018, doi:10.18404/ijemst.428182.

[3] D. A. Major, S. D. Burleson, X. Hu, \& K. Shryock, "Engineering identity as a predictor of undergraduate students' persistence in engineering," presented at the 126th ASEE Annual Conference and Exposition, Tampa, FL, USA, Jun. 16-19, 2019.

[4] C. H. Wasilewski, "Men and women in engineering: Professional identity and factors influencing workforce retention," Ph.D. dissertation, Dept. Industrial/Organizational Psychology, Seattle Pacific University, Seattle, WA, 2015.

[5] M. Eliot, \& J. Turns, “Constructing professional portfolios: Sense-making and professional identity development for engineering undergraduates," Journal of Engineering Education, vol. 100, no. 4, pp. 630-654, Oct., 2011, doi:10.1002/j.21689830.2011.tb00030.x.

[6] D. A. Major, K. R. Reynoldson, X. Hu, S. D. Burleson, and K. Shryock. "Preliminary validity evidence for a brief measure of engineering identity," presented at the 125th ASEE Annual Conference and Exposition, Salt Lake City, UT, USA, Jun. 24-27, 2018. 